\title{
Orientation information in wayfinding instructions: evidences from human verbal and visual instructions
}

\author{
Vanessa Joy A. Anacta · Angela Schwering • \\ Rui Li $\cdot$ Stefan Muenzer
}

Published online: 24 February 2016

(C) The Author(s) 2016. This article is published with open access at Springerlink.com

\begin{abstract}
Although the importance of landmarks for human navigation and for orientation is well accepted, most of today's navigation systems hardly incorporate any landmark information or information supporting orientation. Different from previous research that only addressed turn-by-turn instructions in verbal forms and landmarks at decision points, the present study provides empirical evidence that human-generated wayfinding instructions are not solely turn-by-turn but the majority of instructions provide orientation information. We propose a new classification scheme for identifying information in wayfinding instructions that will not only support orientation but also facilitate construction of mental map. We explored and compared two forms of representations-visual sketch
\end{abstract}

V. J. A. Anacta $(\bowtie) \cdot$ A. Schwering

Institute for Geoinformatics, University of Muenster, Heisenbergstraße 2, 48149 Muenster, Germany

e-mail: v_anac02@uni-muenster.de

A. Schwering

e-mail: schwering@uni-muenster.de

R. Li

Department of Geography and Planning, University at Albany, State University of New York, Arts and Sciences 218, 1400 Washington Avenue, Albany, NY 12222, USA e-mail: rli4@albany.edu

S. Muenzer

Psychology of Education, University of Mannheim, Postfach 103462, 68131 Mannheim, Germany

e-mail: stefan.muenzer@uni-mannheim.de map and verbal instructions. Results revealed that landmark information is important in human wayfinding instructions with particular importance of local landmarks along the route and global landmarks that support orientation. In addition, sketch maps contained more global landmarks than verbal instructions. In contrast to turn-by-turn navigation, we found that many instructions in human route descriptions do not always refer to turning actions but to orientation. We conducted interviews with a set of raters on what they consider helpful information in both forms of representations. These results confirmed our findings and supported that future route descriptions can be more meaningful and helpful when they are enriched with orientation information as they conform to how humans structure wayfinding instructions.

Keywords Local landmarks · Global landmarks · Verbal instructions · Sketch maps · Orientation · Wayfinding

\section{Introduction}

Nowadays, wayfinders often rely on computer-generated route instructions in the form of navigation systems. These route instructions differ in their content and structure from human-given instructions: navigation systems give instructions that draw people's attention solely to the route and its turning points 
(turn-by-turn directions). Many researchers have evaluated the effectiveness of navigation assistance systems during wayfinding (Ishikawa et al. 2008; Muenzer et al. 2012; Brown and Laurier 2012) and showed that turn-by-turn (TbT) systems hardly support spatial learning. Studies in cognitive wayfinding research showed the importance of landmarks at decision points (Denis 1997; Daniel and Denis 1998; Richter and Klippel 2005). In our study, we explore human wayfinding instructions and analyze them regarding the use of information that does not refer to turning actions but supports orientation. We focus on global and local landmarks which are not located at decision points. One goal of this research is to identify orientation information that could be useful to redefine wayfinding instructions deviating from the usual $\mathrm{TbT}$ directions. Based on our findings we intend to develop a new type of navigation system providing instructions that can better support people in learning the spatial layout of the environment and their spatial orientation.

Following Richter and Winter (2014), we define landmarks as any geographic object that is easily perceivable and recognizable and is located permanently at some place. Based on their location, we distinguish global landmarks and local landmarks along the route and at decision points (Winter et al. 2008). In our previous work, we explored how different types of route instructions-machine- versus human-generated instructions-affect acquiring spatial knowledge and orientation ( $\mathrm{Li}$ et al. 2014). Landmarks along the route as well as global landmarks such as city center seemed to have a major influence on knowledge acquisition and spatial orientation. In this paper, we investigate the usage of landmarksglobal landmarks, local landmarks along the route and local landmarks at decisions points-in the verbal instructions and sketch maps. We explore whether different lengths of route and types of representation (verbal and visual) affect the use of landmarks. Furthermore, we analyze orientation information in comparison to turning actions in wayfinding instructions. Schwering et al. (2013) suggested reclassifying navigational instructions based on the criteria of the skeletal descriptions (Denis 1997) but focusing on information that could support spatial orientation. This present study is a comprehensive and systematic follow-up which provides additional insight to the classification scheme of orientation wayfinding instructions. Finally, it confirms the findings with experts judging the helpfulness of our wayfinding instructions.

We expect that humans use many local and global landmarks in their instructions as ways to support orientation for all routes. These landmarks are often not at decision points, thus are not connected to turn information but facilitate orientation. We investigate if the presence of local and global landmarks is evident in both sketch maps and verbal instructions given different types of route. We also expect that the type of instructions has no effect on the information used in instructions. It means that the same type of landmarks and orientation information appear in both forms of representations-visual sketch map and verbal instructions. This paper contributes to existing studies involving landmarks by (a) suggesting a new classification scheme for wayfinding instructions accounting for orientation information; and (b) providing empirical evidence that human-generated wayfinding instructions are not solely $\mathrm{TbT}$, but the majority of instructions give orientation information which helps in acquiring an overview of the environment.

The paper is structured as follows: related work discusses previous studies in cognitive wayfinding research. Afterwards we explain our approach to analyze landmarks and orientation information in route instructions. The study designs, procedures as well as results are in the "Method and results" sections, respectively. The interpretations of results are presented in the discussion, followed by conclusion and outlook.

\section{Related work}

Spatial orientation is one of the spatial abilities important in wayfinding and navigation (Golledge and Stimson 1997). Having good orientation allows one to easily do wayfinding tasks and create spatial judgments when a planned route is disrupted. Thus, it is necessary that a person is oriented in space while navigating to avoid geographic disorientation or getting lost (Montello and Sas 2006). The importance of landmarks in navigation and wayfinding has been widely investigated and agreed upon. Instructions become meaningful if landmarks are included. Particularly more local landmarks (Raubal and Winter 2002) are helpful for pedestrians (Schroder et al. 2011). In fact, humans prefer landmarks over street information 
(Tom and Denis 2003). Steck and Mallot (2000) developed a virtual environment and looked at how people refer to local and global landmarks (mountain, city skyline and TV tower) in the navigation task. They emphasized that a spatial object could first be a global landmark in a wayfinding task and later may serve as a local landmark. In this study, we also investigate landmarks, both local and global, in route instructions from participants.

Researchers have looked at different types of landmarks. Denis (1997) developed the skeletal description framework as a natural set of descriptions containing a minimal set of landmarks wherein landmarks and actions are considered the important components of route instructions and its effectiveness was tested in different areas through wayfinding (Denis et al. 1999; Michon and Denis 2001). However, the authors claim that there is still a need to explore and evaluate the cognitive capacities of individuals when referring to landmarks (Daniel and Denis 1998). In this paper, we extend Denis' skeletal framework to analyze particularly orientation information and landmarks not at decision points.

Lovelace et al. (1999) showed that landmarks at decision points are not the only important elements of route directions. They emphasized that having lengthy or brief instructions do not automatically translate into good or bad verbal instructions. Klippel and Winter (2005) developed taxonomy of landmarks based on its location on the route with particular focus on landmarks at decision points. Similarly, we developed a landmark classification scheme but aside from landmarks at decision points we included both distant and along the route landmarks, which are point and regional types, in the analysis. Ishikawa and Nakamura (2012) tested unfamiliar participants through a wayfinding task and analyzed the landmarks they selected and their location on the route. In their study, landmarks at non-intersections are mostly drawn as more helpful information in navigating in an unfamiliar route with ease. In our study, we also classified landmarks based on their locations on the route. However, we asked people who are familiar with an environment to create route instructions to people who are unfamiliar of the area.

Regarding communicating verbal descriptions, several researchers developed approaches in finding a structure to effectively describe wayfinding instructions (Denis and Zimmer 1992; Allen 1997; Timpf
2002; Klippel 2003; Tenbrink 2014). These instructions could either be based on route knowledge, survey knowledge or a mix of both (Tversky et al. 1999). Weissensteiner and Winter (2004) proposed a model of an effective way of communicating route instructions which is through a narrative. The authors emphasized how important it is for the wayfinder to know her environment. Richter and Klippel (2005) also highlighted that the structure of the environment plays a major role on how wayfinding instructions should be constructed. When map is unavailable, text-based instructions with incorporating more landmarks appeared to be more relevant for pedestrians (Mackaness et al. 2014). People could profit from additional landmark information when given only spoken or textbased instructions. However, it is important that both the direction giver and direction follower establish a common ground to avoid failure in wayfinding (Weiser and Frank 2013). Furthermore, hierarchy of spatial objects is also evident in wayfinding instructions showing how landmarks and paths are clustered based on its functionality (Taylor and Tversky 1992) as well as street networks (Timpf et al. 2005; Tomko et al. 2008) which is useful for route planning (Winter et al. 2008; Steck and Mallot 2000). This is highlighted in the development of the anchor point theory (Golledge and Stimson 1997) emphasizing how reference points anchor known regions in an area that are important in wayfinding. Although there is a presence of hierarchy of spatial objects in our study in terms of qualitative aspect, no extensive analysis on this is discussed in this paper but will be kept for future research.

\section{Analyzing landmarks and orientation information}

In the following section, we introduce the classification for landmarks as well as the classification for orientation information that we developed for the data analysis.

\section{Classification of landmarks}

Following the literature, we classify landmarks into different categories (Fig. 1). While Klippel and Winter (2005) developed a category of landmarks but focusing only on point landmarks and at decision points, our landmark classification includes local landmarks drawn not only as point but also as regional 


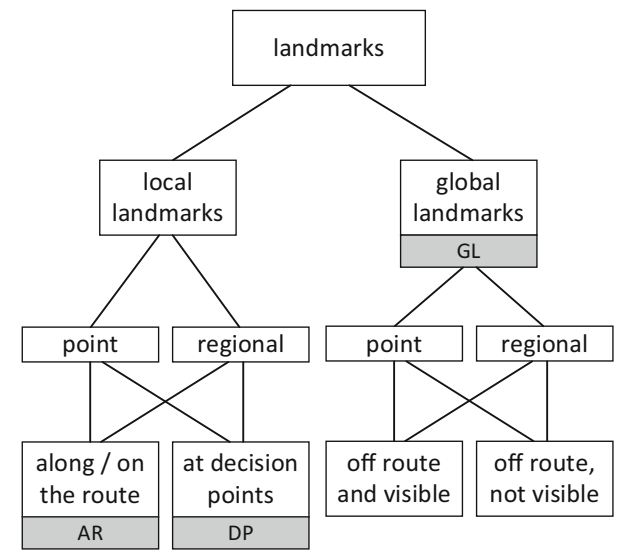

Fig. 1 Classification scheme for landmarks

features including distant landmarks (global landmarks). Local landmarks are visible features located either along the route (AR) or at decision point (DP) where a turning action has to be made. Global landmarks (GL), on the other hand, refer to distant landmarks that are visible or non-visible located off the route. Point features may refer to buildings, tower, and the like; whereas regional features in this study may refer to city center, parks, lakes, and other examples with areal extent. In the following analysis of human wayfinding instructions we decided not to further distinguish landmarks about their spatial extent and visibility. This might become relevant during the development of an orientation wayfinding system, though.

Classification of route instructions including orientation information

Denis (1997) developed a method called "skeletal descriptions" to shorten wayfinding instructions to a minimum description governing cognitive aspects and remaining fully informative. Instructions given in natural languages were deconstructed into a set of mega-descriptions. The mega-descriptions were then extracted to produce a minimum set of instructions containing only landmarks and actions. In his skeletal descriptions, most landmarks were mentioned at decision points while few were mentioned along route segments as skeletal descriptions omit landmarks along the route and descriptions of landmarks. This view has been challenged by Lovelace et al. (1999). We also argue that landmarks along the route are important to maintain orientation. Our goal is not to provide minimum set of route instructions but to analyze information that is essential for orientation. We adapted Denis' framework and propose a new classification scheme (Schwering et al. 2013).

Table 1 summarizes our categorization for wayfinding instructions which are visualized in Fig. 2. Besides Denis' categories prescribing action (PA), describing landmarks (DL), and commentaries (C), we introduced categories addressing orientation using local landmark either along the route (OAR) or at decision point (ODP), orientation using global landmark (OGL), orientation (O) without reference to a landmark, turning action using local landmarks at decision point (TADP), and non-turning action using local landmarks along the route (NTAAR), non-turning action at global landmark (NTAGL) and turning action at global landmark (TAGL). There exists no turning action at a landmark along the route (because the landmark would be at a decision point, if one turns) as well as a non-turning action at a landmark at decision point. ODP, OAR and OGL extend to the original category of 'Introducing a landmark' while TADP, TAGL, NTAGL, and NTAAR is a sub category of 'Action with landmark' in Denis' skeletal description categories. The distinction between OAR and NTAAR is that orientation does not require locomotion.

The identification of orientation information categories is one contribution of this paper wherein orientation would refer to (a) mindfulness of spatial relations of local and global landmarks, providing additional information in structuring the environment being travelled and (b) acquisition of 2-d representation that may help the wayfinder get an overview of the area and which will be useful when error in navigation occurs.

Orientation information in a strict sense $\left(\mathrm{OI}_{\text {strict }}\right)$ comprises the categories O, ODP, OAR, and OGL. In a broad sense ( $\left.\mathrm{OI}_{\text {broad }}\right)$, we can also interpret non-turning actions referring to landmarks (NTAAR, NTAGL) and turning action referring to global landmarks (TAGL) as orientation information, as this information usually communicates confirming information or information relating to the surroundings that supports orientation as well. NTA is not considered as orientation information as it does not refer to landmarks. TADP refers to landmarks which might serve as anchor points and therefore support orientation, however since the landmark is primarily used to identify the location of the turn, we will not classify TADP under orientation 
Table 1 Explanation and examples for the classification scheme for route instructions including orientation information

\begin{tabular}{|c|c|c|c|}
\hline Denis' category & Category name & Abbrev. & Explanation and examples \\
\hline \multirow[t]{3}{*}{ Prescribing action } & Turning action ${ }^{\mathrm{a}}$ & TA & $\begin{array}{l}\text { Change of direction without reference to spatial object, e.g. "Turn } \\
\text { left; Turn left at } 300 \text { meters" }\end{array}$ \\
\hline & Non-turning action $^{\mathrm{a}}$ & NTA & $\begin{array}{l}\text { Continuous movement without change of direction and without } \\
\text { reference to spatial object, e.g. "Continue driving straight" }\end{array}$ \\
\hline & $\begin{array}{l}\text { Orientation (without } \\
\text { landmark) }\end{array}$ & $\mathrm{O}$ & $\begin{array}{l}\text { Describing spatial relation without reference to any spatial object, } \\
\text { e.g. "You are driving north; You are facing north" }\end{array}$ \\
\hline \multirow[t]{3}{*}{$\begin{array}{l}\text { Introducing } \\
\text { landmark }\end{array}$} & $\begin{array}{l}\text { Orientation using local } \\
\text { landmark along the route }\end{array}$ & OAR & $\begin{array}{l}\text { Describing spatial relation with reference to a landmark along a } \\
\text { route, e.g. "You see a church on your right" }\end{array}$ \\
\hline & $\begin{array}{l}\text { Orientation using local } \\
\text { landmark at decision points }\end{array}$ & ODP & $\begin{array}{l}\text { Describing spatial relation with reference to a landmark at a } \\
\text { decision point and no instruction what to do, e.g. "At the next } \\
\text { junction, you see a church" }\end{array}$ \\
\hline & $\begin{array}{l}\text { Orientation using global } \\
\text { landmark }^{\mathrm{a}}\end{array}$ & OGL & $\begin{array}{l}\text { Describing spatial relation with reference to a global landmark } \\
\text { with no instruction what to do, e.g. "To your left is the city } \\
\text { center" }\end{array}$ \\
\hline \multirow[t]{4}{*}{ Action + landmarks } & $\begin{array}{l}\text { Non-Turning action using } \\
\text { local landmarks along the } \\
\text { route }^{\mathrm{a}}\end{array}$ & NTAAR & $\begin{array}{l}\text { Giving instructions not involving change of direction referring to } \\
\text { a landmark along the route, e.g. "You pass the church" }\end{array}$ \\
\hline & $\begin{array}{l}\text { Non-turning action using } \\
\text { global landmarks }\end{array}$ & NTAGL & $\begin{array}{l}\text { Giving instructions not involving change of direction referring to } \\
\text { a global landmark, e.g. "Go straight towards city center" }\end{array}$ \\
\hline & $\begin{array}{l}\text { Turning action using local } \\
\text { landmarks at decision point }{ }^{\mathrm{a}}\end{array}$ & TADP & $\begin{array}{l}\text { Giving instruction involving change of direction referring to a } \\
\text { landmark at decision point, e.g. "Turn left at the church" }\end{array}$ \\
\hline & $\begin{array}{l}\text { Turning action using global } \\
\text { landmarks }{ }^{\text {a }}\end{array}$ & TAGL & $\begin{array}{l}\text { Giving instructions involving change of direction referring to a } \\
\text { global landmark, e.g. "Turn left towards city center" }\end{array}$ \\
\hline \multirow[t]{2}{*}{$\begin{array}{r}\text { Describing } \\
\text { landmark }\end{array}$} & Describing landmarks & DL & $\begin{array}{l}\text { Description of a landmark with no action or spatial relation } \\
\text { involved, e.g. "The church is tall" }\end{array}$ \\
\hline & $\begin{array}{l}\text { Describing environment or } \\
\text { space }^{\mathrm{a}}\end{array}$ & DE/DS & $\begin{array}{l}\text { Describing the environment or space, e.g. "It's a cobblestone } \\
\text { street" }\end{array}$ \\
\hline Commentaries & Commentaries & $\mathrm{C}$ & $\begin{array}{l}\text { Commentary not related to landmark or action, e.g. "It is easy to } \\
\text { find; It is a long route approximately } 2 \mathrm{~km} \text { " }\end{array}$ \\
\hline
\end{tabular}

a Extended categories by authors from Denis' categories of skeletal descriptions

information. Today's TbT navigation systems use TA and TADP (if they use landmarks at all). The remaining categories are classified as supplementary information (NTA, DL, DE/DS, C) as it neither provides orientation nor communicates turns.

\section{Method and results}

Study 1: Usage of landmarks and orientation information

\section{Participants}

A total of 21 participants (11 female, 10 male) took part in the study. They are German native speakers between 19 and 30 years $(M=22.95, S D=2.94)$. They have stayed in the student dormitory for more than 6 months and confirmed to be familiar with the study area. The participants came from different study programs at two universities in the authors' city.

\section{Study area}

The study area is the city center of a medium-sized city in the northwest of a European country. In previous studies we found that city center is the most prominent (global) landmark that people use for orientation (Schwering et al. 2013). We assume that the importance of global landmarks changes with the spatial relation the route has to the global landmark: i.e. it is less likely that participants mention a global (regional) 


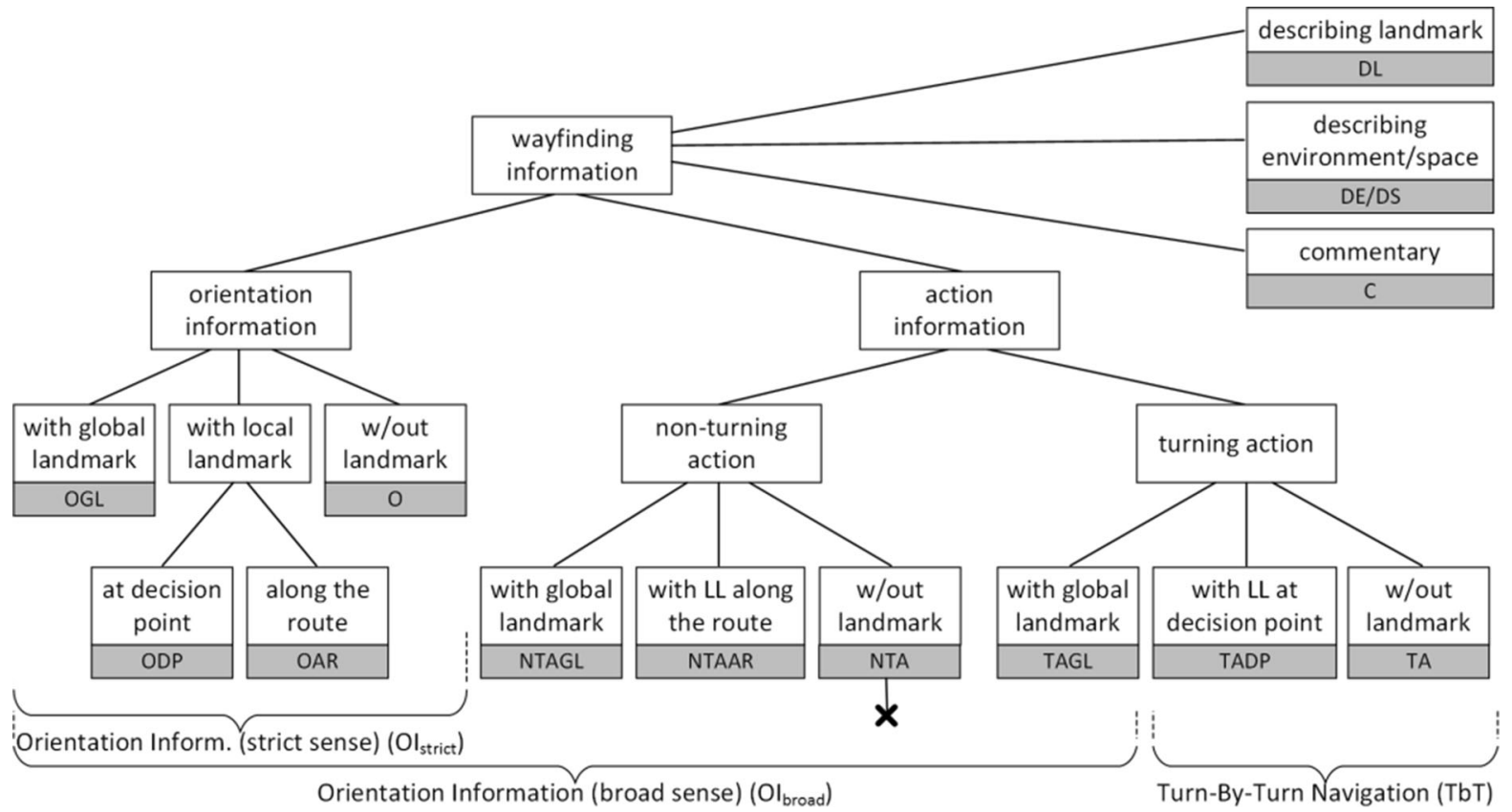

Fig. 2 Classification scheme for route instructions incl. orientation information

landmark such as city center when navigating only within this region. It is more likely that participants mention the landmark when they start outside the region and cross or enter it, or when they navigate between two city centers. Thus, we chose three routes (i) going through the city center (Route 1: within city), (ii) going past the city center (Route 2: across city) and (iii) between two cites (Route 3: inter-city). Origin and destination of Routes 1 and 2 are visualized in Fig. 3: Route 1 starts at the train station and ends at the
Fig. 3 Map of the study area. (Color figure online)

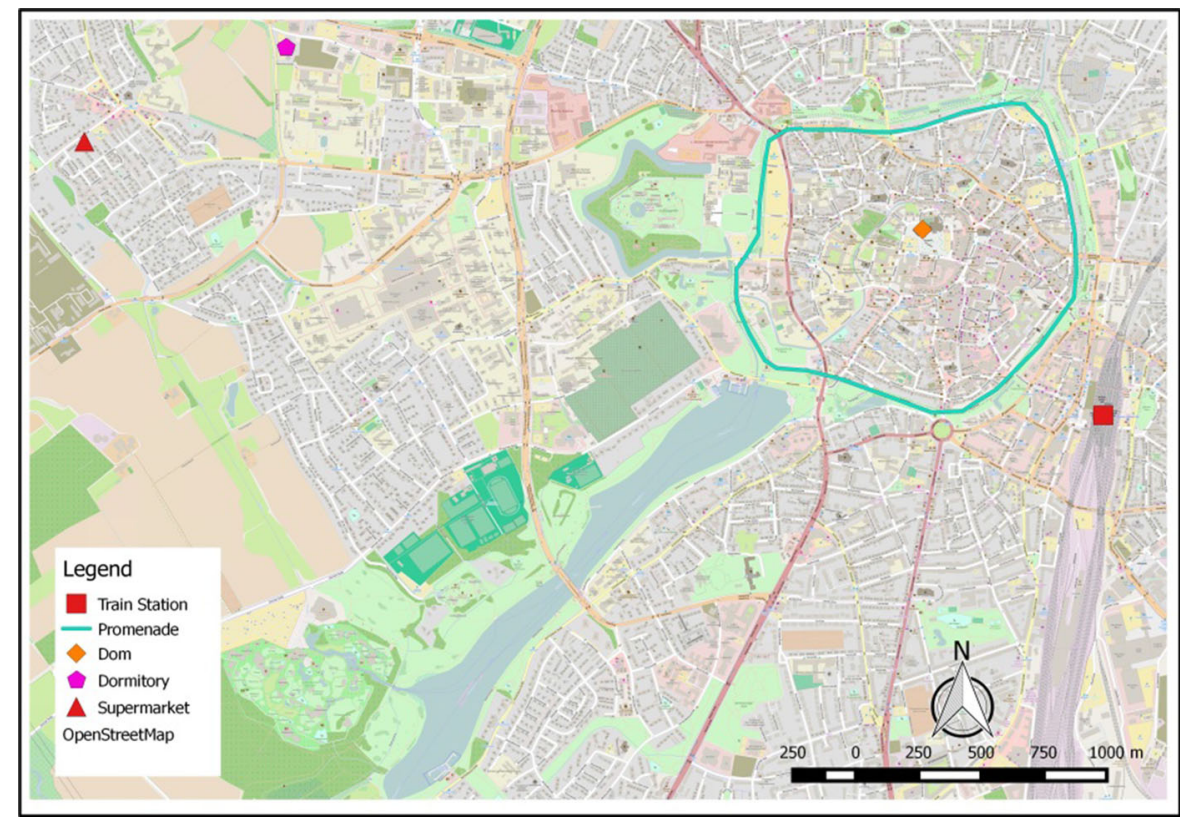


cathedral (Dom), both located within the city center. The approximate length of Route 1 is $1.2 \mathrm{~km}$. Route 2 covers the outskirts of Muenster city center. The route starts at a supermarket located outside the city center and ends at the train station, within the city center. The route distance is approximately $5 \mathrm{~km}$. Route 3 is a longer route as it covers a route from the city of Muenster to another city in Germany which is the participant's hometown. We expect that these routes have different relations to several global landmarks in the environment, thus help us to investigate whether people only include information situated on the route or also include information which is off the route and may support global orientation.

Figure 3 visualizes the location of the relevant spatial objects for reference in the discussion. It shows the location of the student dormitory where we conducted the study as well as the location of the starting point and the goal. It visualizes also frequently mentioned global landmarks for our study area such as the castle (Schloss) and the green belt around the city center (Promenade) which is a bike and pedestrian ring-like path encircling the city center and oftentimes considered as the boundary of the city center.

\section{Procedure}

We conducted the study in one of the university's dormitories. The students living in this dormitory took part voluntarily and received $10 €$ per hour as remuneration. Before the tasks, the participants were asked to fill in questionnaire to assess their level of familiarity with the city. In the first part of the study, participants were asked to draw a route map for three different routes each on an A4 sized paper. No specific style or format for drawing the map was given. In the second part, the participant described the same routes by typing the route instructions using a laptop without referring to the sketch map previously drawn. No time limit was given for both tasks. The three routes used were as follows:

- Route 1 (within city): at the train station, someone new in the area asks you how to go to the Cathedral by bike. Please draw a map ${ }^{1}$ with the route from the train station going to the Cathedral.

\footnotetext{
${ }^{1}$ In the second part of the task, we replaced "draw a map" by "describe the route".
}

- Route 2 (across city): at the supermarket, someone new in the area asks you how to go to the train station by bike. Please draw a map with the route from the supermarket to the train station.

- Route 3 (intercity): you invite your flatmate to a family gathering in your hometown. S/he asks you how to come from the student dormitory to the gathering by car. Please draw a map of the route he/she will take from the student dormitory to your place.

\section{Results}

Usage of local and global landmarks Participants first drew the sketch map and later described the route without referring to the map and it showed that for within city routes, $28 \%$ of the participants for Route 1 and $38 \%$ for Route 2 described a different route in the verbal instructions from what they have previously drawn in their sketch maps. Table 2 shows the results for different types of landmarks used in verbal instructions and sketch maps for the three different routes. Analyzing the overall usage of landmarks, we found that participants used landmarks similarly in both verbal instructions and sketch maps. A two-way (route and representation forms) Chi-square test did not result in significant contingency $(p=.94)$. That is to say that participant's use of landmarks is independent from the type of presentation (sketch maps or verbal instructions) and route types. The first row in Table 2 presents the average number of landmarks mentioned in both representation forms for all three routes.

Analyzing types of landmarks concerning form of representation and routes, we applied a three-way (route, landmark type, representation form) Chisquare design. Although by just looking at the frequency, that GL has been more referred to in Route 3 , results also indicated that with respect to the specific type of landmarks, the usage of those landmarks is independent from both route type and representation type, $p=.37$ (the other two Chi-square tests within each representation form are the same as those reported in the previous paragraph).

Table 3 shows how many participants included landmarks in their instructions. Nearly all participants included GL in either forms of representation in Route 3. This means that they usually consider global 
Table 2 Frequency of landmarks given by participant in visual or verbal forms

\begin{tabular}{|c|c|c|c|c|c|c|}
\hline & \multicolumn{2}{|l|}{ Route 1} & \multicolumn{2}{|l|}{ Route 2} & \multicolumn{2}{|l|}{ Route 3} \\
\hline & $\begin{array}{l}\text { VD } \\
M(S D)\end{array}$ & $\begin{array}{l}\mathrm{SM} \\
M(S D)\end{array}$ & $\begin{array}{l}\mathrm{VD} \\
M(S D)\end{array}$ & $\begin{array}{l}\mathrm{SM} \\
M(S D)\end{array}$ & $\begin{array}{l}\text { VD } \\
M(S D)\end{array}$ & $\begin{array}{l}\mathrm{SM} \\
M(S D)\end{array}$ \\
\hline Total landmarks & $4.91(4.07)$ & $4.57(3.63)$ & $8.33(5.17)$ & $8.48(3.93)$ & $10.09(6.56)$ & $7.81(3.79)$ \\
\hline AR & $3.62(2.33)$ & $2.52(2.73)$ & $5.52(2.68)$ & $5.00(2.13)$ & $4.90(2.86)$ & $2.48(1.97)$ \\
\hline DP & $0.86(1.06)$ & $1.05(1.24)$ & $1.86(1.42)$ & $1.76(1.09)$ & $1.86(1.39)$ & $1.81(1.37)$ \\
\hline GL & $0.43(0.68)$ & $1.00(1.00)$ & 0.95 (1.07) & $1.71(1.19)$ & $3.33(2.31)$ & $3.52(1.81)$ \\
\hline
\end{tabular}

Table 3 Participants including at least one landmark in their instructions

\begin{tabular}{|c|c|c|c|c|c|c|}
\hline & \multicolumn{2}{|l|}{ Route 1} & \multicolumn{2}{|l|}{ Route 2} & \multicolumn{2}{|l|}{ Route 3} \\
\hline & $\mathrm{VD}$ in $\%$ & $\mathrm{SM}$ in $\%$ & $\mathrm{VD}$ in $\%$ & $\mathrm{SM}$ in $\%$ & $\mathrm{VD}$ in $\%$ & $\mathrm{SM}$ in $\%$ \\
\hline Total landmarks & 95 & 95 & 100 & 100 & 100 & 100 \\
\hline $\mathrm{AR}$ & 95 & 81 & 100 & 100 & 95 & 76 \\
\hline DP & 48 & 52 & 76 & 90 & 81 & 86 \\
\hline GL & 33 & 67 & 57 & 81 & 90 & 95 \\
\hline
\end{tabular}

landmarks to be important for intercity routes both in sketch maps and verbal instructions. In Routes 1 and 2,67 and $81 \%$ of the participants included global landmarks in their visual route instructions, respectively. The commonly drawn global landmarks in Route 2 are the castle of Muenster, the city center and the Promenade. Local landmarks along the route also play an important role in route instructions. All participants included AR in their verbal instructions for Route 2 and nearly all (95\%) for Route 1 and Route 3. All participants drew AR in sketch maps of Route 2 and most drew them in sketch maps of Route 1 (81\%) and of Route 3 (76\%). Surprisingly, several participants did not include any DP in their instructions.

Figure 4 shows two examples of sketch maps and the landmarks drawn illustrating in particular the global landmarks drawn. The red line highlights the route taken from starting point to the destination. The maps contain examples of visible and non-visible global landmarks as well as local landmarks along the route or at decision point. For example, in the sketch map of Route 2, the participant included the global landmarks castle (Schloss) and Ludgeriplatz which are not visible from the route. Both sketch maps give an overall layout of the city by showing regional global landmarks such as the Promenade (left map on Route 1) and the Ring road (right map on Route 2).
In verbal instructions, the city center is a common regional feature mentioned in the instructions, e.g. one participant said: 'From the main entrance of the train station, cross the street and go towards the city center... ${ }^{2}$ The regional feature city center is mentioned to orient the person from starting point. Most participants in Route 2 mentioned the castle without the intention for the wayfinder to go past it, rather taking the direction going towards it. The castle was not visible from the route. For example, one of the participants stated: „...From there you go to the direction of the castle. But, you turn left before the castle at Muenzstrasse... ${ }^{3}$ For Route 3 instructions; participants usually described the direction of travel to a city which is not the destination such as: After leaving the motorway, turn left and drive in the direction of Ikea. But before Ikea, after the first trafficlights, turn left onto the bridge across the motorway ${ }^{4}$ Although the participant mentioned the furniture

\footnotetext{
$\overline{2}$ Vom Haupteingang des Hauptbahnhofs aus der Straße ueberqueren und immer weiter geradeaus in die Innenstadt hinein gehen...

3 ...Da faehrst du rechts in Richtung Schloss. Du faehrst aber schon bevor du am Schloss bist wieder links in die Muenzstraße....

${ }^{4}$ Nach der Ausfahrt links Richtung Ikea fahren, vorher aber nach der ersten Ampel links ueber die Autobahnbruecke fahren....
} 


\section{Route 1}

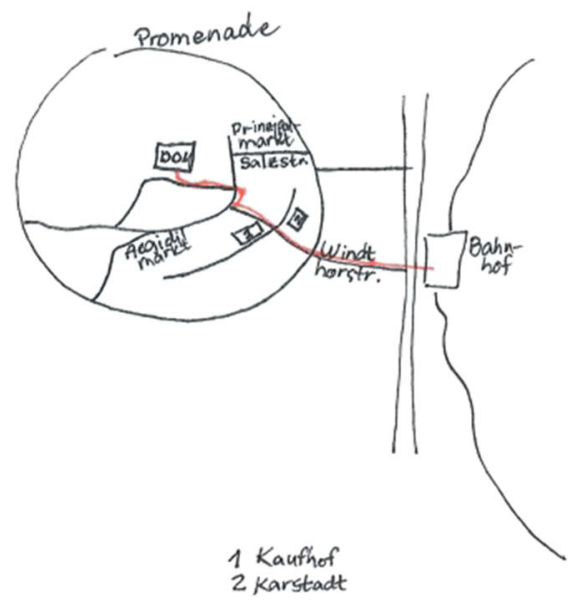

Route 2

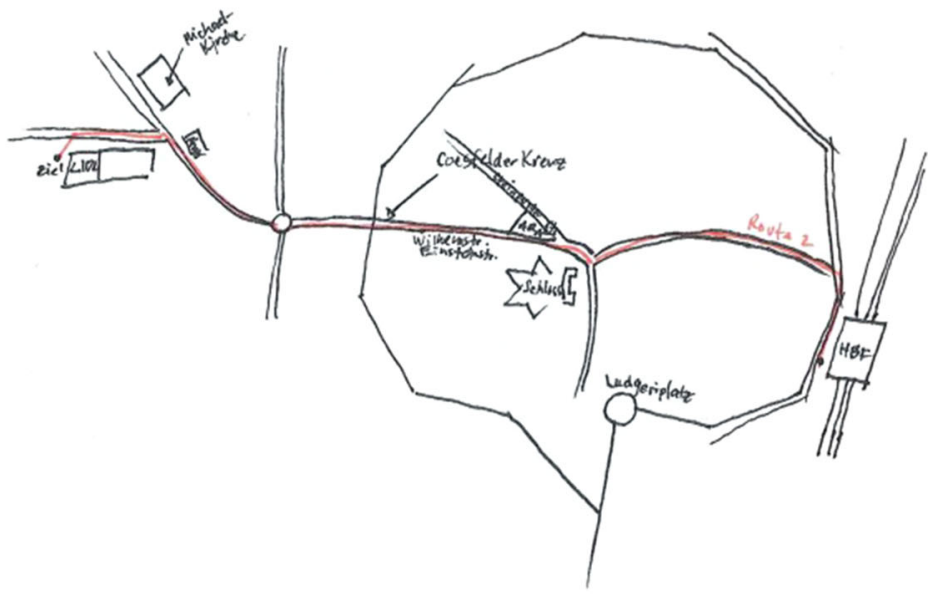

Fig. 4 Examples of route sketch maps showing global and local landmarks. (Color figure online)

shop, it was only used to refer to the direction of travel without the intention to go past it.

\section{Usage of route instructions including orientation} information in verbal descriptions We analyzed orientation information in the verbal route instructions using the previously explained classification scheme. We are particularly interested in categories related to orientation in the strict sense or in the broad sense. Table 4 shows the mean $(M)$ and standard deviation $(S D)$ of the frequency of mention of different categories from the participants' route instructions.

The results showed that most of the verbal instructions referred to NTAAR as the most frequently mentioned category. $37 \%$ of all verbal instructions were classified as NTAAR. This was similar across all routes: for Routes 1, 2 and 3, 32, 38 and $40 \%$ of the instructions are NTAAR, respectively. The second most frequent class in verbal route instructions is the TADP (24\% of all instructions).

Analyzing orientation information in the strict sense, results revealed that $13 \%$ of all instructions referred to $\mathrm{OI}_{\text {strict }}$. The frequency was highest for Route $1(19 \%)$ and lower for Routes 2 and 3 (12 and $10 \%$ ). Looking at orientation information in the broad sense, more than half of the information referred to

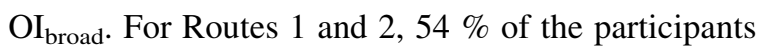
mentioned orientation information in the broad sense and for Route 3, $63 \%$. This is an important result: more than half of the instructions people give facilitate orientation. They are not related to any turn information. People used relatively few TbT instructions: $21 \%$ for Route $1,31 \%$ for Route 2 and $27 \%$ for Route 3 . This is a fundamental difference to today's TbT navigation systems.

We applied a two-way (route and instruction category) Chi-square test to investigate the contingency of each route instruction category and route. The result showed that the use of specific instruction category is contingent to the type of routes, $x^{2}$ (24, $\mathrm{N}=300)=44.13, p<.05$. This is clearly shown in Table 4 that O, ODP, and OGL have sometimes zero frequency in some routes. This indicates that participants did not particularly use this instruction type for a specific route as for other routes to support orientation. Once we removed these cases with zero frequency $(\mathrm{O}, \mathrm{ODP}$, and OGL), the remaining individual categories showed marginal contingency with routes, $p=.07$.

Since we were interested in the functions that each instruction type support a certain action, we aggregated the categories at fine levels into function-based groups: $\mathrm{OI}_{\text {strict }}$, Turning Actions (TA, TADP, and TAGL), and Non-turning Actions (NTA, NTAAR, and NTAGL). A Chi-square test of the similar design implied that the use of instructions to support these three major actions in wayfinding is independent from the type of route and share similar frequency for each route, $p=.25$. In particular, the aggregated results showed that most instructions were to support non- 
Table 4 Categorized wayfinding information in verbal route instructions provided by participants

\begin{tabular}{llll}
\hline Category & $\begin{array}{l}\text { Route 1 } \\
M(S D)^{\mathrm{a}}\end{array}$ & $\begin{array}{l}\text { Route 2 } \\
M(S D)\end{array}$ & $\begin{array}{l}\text { Route 3 } \\
M(S D)\end{array}$ \\
\hline TA & $0.14(0.48)$ & $0.57(0.81)$ & $0.52(0.81)$ \\
NTA & $1.86(1.80)$ & $0.95(1.12)$ & $0.71(1.98)$ \\
O & 0.0 & 0.0 & $0.29(0.56)$ \\
OAR & $2.05(2.22)$ & $1.62(1.50)$ & $1.19(1.21)$ \\
ODP & $0.19(0.60)$ & $0.05(0.22)$ & 0.0 \\
OGL & 0.0 & $0.10(0.44)$ & $0.43(0.87)$ \\
NTAAR & $3.76(1.79)$ & $5.81(2.98)$ & $7.57(4.34)$ \\
NTAGL & $0.05(0.22)$ & $0.33(0.48)$ & $1.29(1.52)$ \\
TADP & $2.33(1.53)$ & $4.09(1.61)$ & $4.67(2.42)$ \\
TAGL & $0.29(0.56)$ & $0.33(0.48)$ & $1.24(1.51)$ \\
DL & $0.33(0.48)$ & $0.48(0.81)$ & $0.29(0.64)$ \\
C & $0.19(0.40)$ & $0.52(0.87)$ & $0.76(1.04)$ \\
DE/DS & $0.48(0.60)$ & $0.33(0.58)$ & $0.14(1.04)$ \\
\hline
\end{tabular}

${ }^{a}$ Mean $(M)$ and standard deviation $(S D)$

turning actions $(28.57 \%$ for Route $1,46.70 \%$ for Route 2, and $50.12 \%$ for Route 3 ) followed by the turning actions $(23.67 \%$ for Route $1,32.91 \%$ for Route 2, and $33.67 \%$ for Route 3 ) and the $\mathrm{OI}_{\text {strict }}$ instructions (19.18\% for Route 1, $11.60 \%$ for Route 2, and $9.97 \%$ for Route 3 ).

Looking at orientation information in a broad sense, we aggregated the categories into instructions referring to $\mathrm{OI}_{\text {broad }}$ instructions and $\mathrm{TbT}$ instructions. A Chi-square test of the similar design implied that the use of instructions to support these three aggregated categories in wayfinding is independent from the type of route and share similar frequency for each route, $p=.48$.

Study 2: Helpful information in route instructions

\section{Participants}

Five university employees from different institutes who are familiar with the city of Muenster rated both sketch maps and verbal instructions. They were compensated $€ 10$ per hour.

\section{Procedure}

The raters first received all verbal route instructions and then all sketch maps created by the participants in study 1 . They were asked to categorize the instructions into good, $O K$, and poor groups based on their own understanding with no criteria given for as long as these instructions will support someone unfamiliar with the environment to find the destination. Then, we conducted a short interview about the information they find helpful in the route instructions. The interview question states: What helpful information did you find in the route instructions such that someone can easily navigate in an unfamiliar environment?

\section{Results}

We analyzed the interviews from the raters with a content analysis (Krippendorff 2003) approach. We transcribed the interviews and identified keywords about the helpful information they found in the route instructions. Then, we sorted them into the same categories we used in our previous analysis (landmark classification and classification scheme including orientation information) and order them based on frequency. This illustrates whether the helpful information falls into the categories we previously identified. The raters mentioned several times that they used similar information for both forms of representation. One of them mentioned that too many TbT instructions are not helpful especially when the person makes a wrong turn and there is the absence of landmarks and street names. The rater emphasized that this makes the person too focused on the route and not on the environment and the person has no chance to make detours. For sketch maps, correct labels are important as well as additional information like landmark and street descriptions.

Table 5 enumerates the helpful information the raters found in both forms of representation. In verbal instructions, most of the landmarks (46\%) are AR followed by $30 \%$ of local landmarks at DP and then $24 \%$ of global landmarks. With sketch maps, $42 \%$ of the information that raters considered helpful are AR while 32 and $26 \%$ referred to DP and GL, respectively. Among the landmarks, AR is often included with DP and GL mentioned almost equally often. This means that not only local landmarks are considered helpful landmarks to be shown in sketch maps but also global landmarks.

We assigned values to the three ordered categories with higher weight given to 'good' route instruction. We used the intraclass correlation coefficient (ICC) in measuring reliability of the raters (Shrout and 
Table 5 Landmarks mentioned as helpful information

\begin{tabular}{|c|c|c|c|}
\hline \multicolumn{2}{|c|}{ Verbal instructions } & \multicolumn{2}{|l|}{ Sketch maps } \\
\hline \multicolumn{2}{|c|}{$\begin{array}{l}\text { Hierarchical information (towards city center). Promenade. } \\
\text { Lackkunst Museum. City Hall. Traffic light. Distance } \\
\text { information. Gasoline station. Remarkable buildings and } \\
\text { houses. Bus stops. Treff hotel. Well-known streets (i.e. } \\
\text { Prinzipalmarkt, Buelt, Eisenbahnstrassse). Theater. Big } \\
\text { buildings. Sparkasse bank. Shops. Mensa (refectory). LWL } \\
\text { bldg.. Roundabout. Old town (City Center). City names. Major } \\
\text { street names. Shopping stores (Karstadt and Galeria Kaufhof) }\end{array}$} & \multicolumn{2}{|c|}{$\begin{array}{l}\text { Promenade. Shops. Gas station. Roundabout. City names. Big } \\
\text { buildings. Points (landmarks) in between. Confirmation } \\
\text { information. Mensa. Information at decision points. Control } \\
\text { landmarks (off route). Bus stops. City center. Cathedral. City } \\
\text { Hall. Castle. Buddenturm (tower) }\end{array}$} \\
\hline $\mathrm{AR}$ & $4.2(1.48)$ & $\mathrm{AR}$ & $3.6(1.95)$ \\
\hline DP & $2.8(2.28)$ & DP & $2.8(0.45)$ \\
\hline GL & $2.2(1.48)$ & GL & $2.2(1.48)$ \\
\hline Total landmarks & $9.2(5.24)$ & Total landmarks & $8.6(3.88)$ \\
\hline
\end{tabular}

Fleiss 1979; Hallgren 2012) as we were interested in assessing the degree of reliability of all ratings across the participants, in particular the mean of their ratings, such that a higher rating by one rater corresponds with the higher rating from another not necessarily agreeing on the same values. The raters were not given further instructions and criteria in the rating task. They were simply asked to sort out the instructions based on the three categories. The reliability results based on consistency for all the sketch maps for average measures was high, $\operatorname{ICC}(2,5)=$ $.81, .83$, and .89 for Routes 1,2 and 3, respectively. For single measures, the results are $\operatorname{ICC}(2,1)=.47, .49$, and .63 for the same routes. Figure 5 shows the sketch maps which were rated 'good' by all raters and we highlighted the global landmarks. It showed many details and contained all the landmark classifications we used in the analysis.

With regard to verbal instructions, not all routes resulted high degree of reliability in terms of consistency among the raters. Route 1 incurred higher reliability with $I C C(2,5)=.74$ for average measures compared with Routes 2 and 3, with $\operatorname{ICC}(2,5)=.46$ and .69 , respectively. For the single measures, the results are $\operatorname{ICC}(2,1)=.36, .15$, and .31 for Routes 1 , 2 , and 3 , respectively.

In classifying the helpful information based on our classification scheme for route instructions, Table 6 shows the mean and standard deviation of the frequency of helpful information mentioned by the raters per category. OAR was most frequently mentioned $(26 \%)$ and second most frequent was NTAAR
(20\%). Looking at aggregated categories, $51 \%$ of helpful information referred to orientation information (in the strict sense) and $83 \%$ in the broad sense. One of the raters highlighted the importance of a hierarchical structure of landmarks such as including city center. Some other helpful information in the verbal instructions includes confirming information and combination of turn instructions with travel direction (e.g. after leaving the highway turn right towards Berlin).

The results confirmed that landmarks at TADP are not the only helpful information in route instruction but also NTAAR. Apart from OAR and ODP, OGL also appeared to be helpful information.

\section{Discussion}

Local and global landmarks

Our study confirms the claim that human-given instructions differ from machine-generated ones by the rich presence of landmarks (Dale et al. 2002). The results revealed frequent usage of global and local landmarks regardless of the form of representation and the route. In the verbal instructions, participants used landmarks to orient a person with either local or global landmarks (sometimes even non-visible global landmarks). While the importance of local landmarks at decision points is well-known in navigation, this study showed that people extensively use landmarks along the route and global landmarks in both sketch maps 


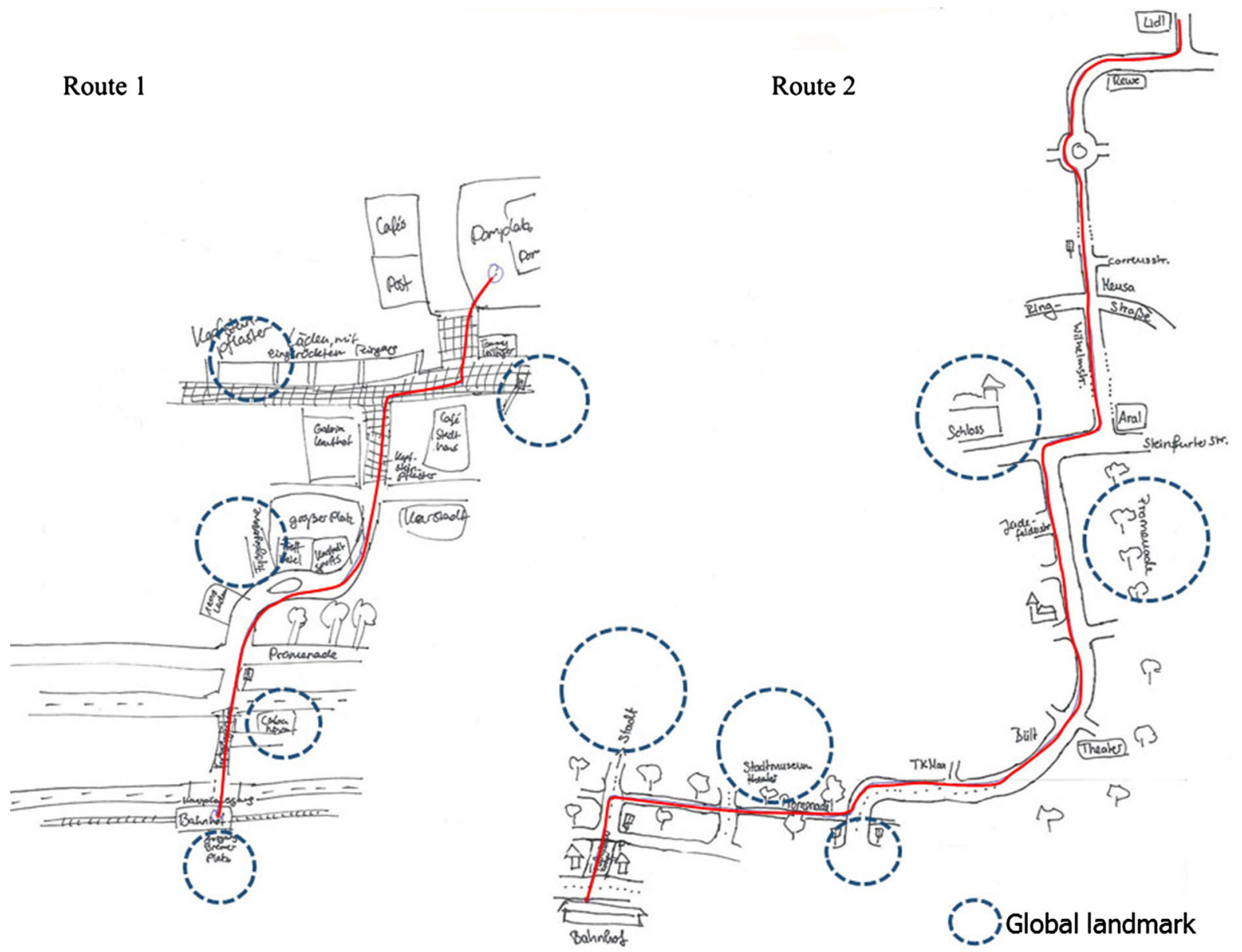

Fig. 5 Examples of highly-rated sketch maps (red line indicates the route). (Color figure online)

Table 6 Categories in verbal instructions provided by raters

\begin{tabular}{ll}
\hline Category & $M(S D)$ \\
\hline TA & 0.0 \\
NTA & 0.0 \\
O & $0.2(0.45)$ \\
OAR & $5.0(1.73)$ \\
ODP & $2.4(1.52)$ \\
OGL & $2(1.41)$ \\
NTAAR & $3.8(1.09)$ \\
NTAGL & 0.0 \\
TADP & $2.2(1.48)$ \\
TAGL & 0.0 \\
DL & $2.0(2.0)$ \\
C & $0.2(0.45)$ \\
DE/DS & $1.0(1.41)$ \\
\hline
\end{tabular}

and verbal instructions as helpful information in wayfinding.

Global landmarks appeared in all route instructions with a similar fashion. Although global landmarks appeared in all types of routes (within and across city center routes) with more in longer route (intercity), its role for global orientation during wayfinding is not extensively studied. Our results show that in the verbal instructions, global landmarks are used as reference objects for direction of travel. These may not be the destination, but participants used them in directing the wayfinder. In addition, a global landmark can contribute to survey knowledge by shaping the structure of a place. For instance, many people use the Promenade in Muenster as a boundary of the city 
center. Hence, the sketch maps of several participants showed a hierarchical structure by including Promenade as regional global landmark. These known landmarks which are typical of the authors' city may have led to the participants' assumptions that these spatial features are common knowledge especially in central Europe wherein some cities have the so-called ring road that surrounds the city center, thus including it in their route instructions. In this case, the results might be more valid to European cities having the same spatial layout. However, we also plan to investigate a similar type of study for other cities such as those with grid-like structure.

To reiterate, the routes chosen were within city and intercity with bike and car as mode of transportation, respectively. The results showed that the types of landmarks mentioned may differ on the route type with more global landmarks mentioned in the longer routes. This is observed in verbal descriptions wherein there is an increase use of global landmarks with a longer route that requires driving (Schwering et al. 2014).

Orientation information in verbal instructions and sketch maps

Existing studies use verbal instructions in investigating importance of landmarks in route instructions but still with focus in TbT fashion. This paper looked at both sketch maps and verbal instructions in analyzing local and global landmarks which are not often addressed in many wayfinding research. Both representations appear comparable in terms of the types of landmark information participants include. There are elements which are mentioned in the verbal instructions and which may not be present in the sketch maps. Although, there may be some similarities of elements found in both representations, it still showed interesting and valid results. Verbal instructions and sketch maps show high presence of landmarks in the instructions. Global landmarks are more prominent in sketch maps than verbal instructions. We believe that this is because maps are inherently 2-dimensional and configurational. Thus, it includes the context of environment in which a route is given.

Our study shows that some types of landmarks mentioned are common for routes regardless of their types. This is very dominant with the use of local landmarks either they are along the route or at decision points. The use of local landmarks along routes is particularly used in verbal instructions for supporting orientation. But the use of global landmarks seems to be associated with the type of routes. In this study, global landmarks are frequently mentioned in a long route at intercity level for both verbal instructions and sketch maps.

It was clearly emphasized in the task that the route instructions the participants will provide are intended for newcomers in the city. It occurred that most of them mentioned some off-route landmarks which we also included in our analysis since our purpose is to investigate orientation information in human-generated wayfinding instructions contrary to the study of Denis (1997) on skeletal descriptions which was to produce a minimal set of instructions.

Based on our results, the important components of wayfinding instructions that will help in orienting oneself in the environment are the inclusion of more AR that support confirmation (i.e., NTAAR) and orientation (i.e. OAR) for shorter routes and inclusion of more GL for longer route. However, this current paper does not intend to provide the formal criteria but present empirical evidence on other relevant elements that humans include which are oftentimes eliminated in investigating wayfinding instructions. The results will later be used for future studies in developing computer-generated wayfinding aids which will not only provide meaningful TbT instructions but also orientation information that will help a person to slowly build a cognitive map.

Route instructions including orientation information

The results from different routes show that landmark for orientation play a major role in human-given wayfinding instructions. This supports our finding from the previous study that AR landmarks and GL are important in wayfinding.

The high frequency of landmarks used for orientation shows that participants tend to orient wayfinder with both local and global landmarks when giving instructions regardless of route type. In general, OAR was mentioned to support one's orientation during route following. It is not surprising that in the verbal descriptions, the instructions contain more OAR in all three route types. This confirms the study of Ishikawa and Nakamura (2012) wherein participants often 
include landmarks at non-intersections as confirming information specifically when there is less number of turns. Although local landmarks are the highly referred type of landmark, orienting to a global landmark is also common but mostly used for the longer route at intercity level (Route 3 ). The use of cardinal directions for orientation was only used for the intercity route as well but few participants mentioned it in their route instructions. Orientation with GL was hardly mentioned in Route 1, the shortest route.

The results also showed that participants often mention local landmarks along the route with no turning action (NTAAR). Although TADP is also mentioned in the instructions as those commonly used in existing TbT navigation systems, NTAAR occurred most frequently in all three routes. This implies that not only landmarks with turning actions (TADP) should be included in verbal instructions but also more landmarks with non-turning actions, which are the major component for this human-given instructions to support orientation in wayfinding. Furthermore, results show that when there is no presence of landmarks, instructions tend to lead wayfinders with more references to non-turning actions.

Turn-by-turn instructions from today's navigation systems have long been acknowledged in providing instructions for faster and more successful navigation. However, these types of instructions hinder spatial learning while there are types of visualizations in mobile devices that could support orientation learning incidentally (Muenzer et al. 2012). Thus, we propose a new way of structuring wayfinding instructions which deviates from purely procedural instructions but a system that supports cognitive representation of the environment during wayfinding. Route instructions should not only help a person find a specific destination but also support one's spatial orientation especially if a sudden failure of the system occurs. The presence of global directions and landmarks, visible or non-visible, could be useful later for someone to recover from wayfinding errors and in relating oneself in the environment with respect to other landmarks. For example, the use of the castle in the route instructions for Route 2 which was included by many participants. This might not be visible along the route but this type of global landmark can be used as orientation information when navigating through the environment. Signage may be helpful directing the person to that place even if it is not the destination and there is no intention to go past it. This was also evident in the intercity route (Route 3) wherein participants often directed the wayfinder to a city (i.e. "Drive towards Berlin") without even reaching or visiting the place. Participants somehow find this type of instruction more useful instead of providing cardinal directions (i.e. "Go north") when driving on the highway. Hence, our study provides an alternative way of generating route instructions by incorporating additional information that helps communicate directions intuitively to the user and at the same time aids in spatial learning.

Usage of orientation-related categories as helpful information for navigation

The rating results and interview confirmed our findings in the first study regarding the type of information helpful in the verbal instructions and sketch maps. This supports our argument that people prefer additional landmarks in wayfinding instructions although they might not be necessary for finding the way. The reliability of ratings is higher in sketch maps than in verbal instructions. This may indicate that the raters could have used the same basis or criteria in judging the maps. They have mostly agreed on which sketch map is to be rated good or poor. This result is not surprising for a 2-dimensional representation as it provides a structural overview of the environment. The verbal instructions of Route 2, however, incurred a lower reliability among raters compared to the other routes. This is not surprising since no additional information was given to the raters when they were asked to sort out the route instructions unlike the study of Denis (1997) on verbal descriptions wherein some criteria were explicitly mentioned in the rating task. Apart from not giving additional guidelines in rating the instructions, another possible explanation for low reliability in Route 2 could be that participants took different paths from the most common one as shown in Fig. 4. Unlike Route 1 for which almost all participants drew the same path from the train station to the cathedral.

Almost half of all helpful information in the verbal instructions was AR, which are usually confirming and orientation information. Out of all these AR, most functions that they serve are OAR. In addition, raters also considered OGL as helpful information in verbal instructions. This includes directing wayfinders to an 
off-route landmark which is either a point or regional feature. The highly rated sketch maps showed presence of landmarks not only found along the route but also those which are located off the route (global landmarks). Almost half of the landmarks that they considered helpful information were also AR. In sketch maps, raters almost equally referred to DP and GL. They explained that global landmarks are helpful for orienting someone in the unfamiliar environment giving someone a sense when travelling off the designated route. This confirms the findings that global landmarks are often represented visually on sketch maps.

Aside from landmarks, the raters mentioned in the interview that visualizing the complete intersections and drawing of curve structure which resembles the actual street network are some of the criteria they used when rating the sketch map. This is because small winding streets are typical of the authors' city particularly in the city center which are sometimes made up of cobblestones. Hence, describing landmarks and the environment is also considered helpful in the route instructions. An example is shown in Fig. 5 for Route 1 wherein the participant drew a road in checkered pattern referring it as a cobblestoned street.

\section{Conclusion and outlook}

Previous studies have long been investigating the various roles of landmarks in navigation but do not substantially address orientation problems when following route instructions. By proposing a new classification scheme for wayfinding instructions accounting for orientation information that will facilitate the formation of a mental map, the present study explores and compares two forms of representationsvisual sketch map and verbal instructions providing empirical evidence that human-generated wayfinding instructions are not solely TbT, but the majority of instructions provide orientation information. We suggest that landmark information is important in human wayfinding instructions and demonstrates the particular importance of local landmarks along the route and global landmarks that supports orientation. This is in strong contrast to today's navigation systems that primarily use TbT information which neglect both local landmarks along a route and global landmarks. Landmarks in available systems are usually located at decision points, if at all. The study provides empirical evidence for proposing new navigation systems that support spatial orientation by providing information on how features are spatially related to get an overview of the area. If these are clearly-structured, these could motivate spatial layout learning to wayfinders thereby capturing configural knowledge of the environment. The results emphasize that in giving wayfinding instructions, landmarks at decision points are not the only features to be considered, but also those situated along the route. Besides local landmarks, global landmarks appear to be important elements in both sketch maps and verbal instructions. In the verbal instructions, participants usually provide a global orientation by introducing a distant point or regional landmark. This often refers to the direction of travel, which is not necessarily the destination itself. In sketch maps, global landmarks appeared most frequently in the intercity route whereas local landmarks are included in all routes (within, across and intercity). All remaining analyses did not reveal any difference between the routes: landmarks AR and GL as well as the categories NTAAR and TADP were frequently used independently of the route. One interesting aspect which appeared in the study is the point landmark feature drawn within a regional landmark. Some maps were structured presenting a '(point) landmark within a (regional) landmark' concept showing a hierarchy of global regional features and local landmarks. The physical layout of the city might have influenced how some participants structured their sketch maps. This aspect of hierarchy is not extensively investigated here and will be analyzed in our future studies.

Although there are differences between verbal instructions and sketch maps, both forms of representation presented similar findings of what information needs to be included in giving wayfinding instructions. The raters' criteria and the helpful information that they mentioned confirmed the importance of orientation information in wayfinding instructions.

For future work, we aim to develop a system generating wayfinding instructions that include local landmarks (also along the route) and global landmarks to give on-route confirmation and to enhance spatial orientation. The proposed orientation wayfinding instructions contain a hierarchical structure of spatial elements in contrast to the simple TbT routing instructions. We plan to develop a prototype on mobile devices showing a map with different 
categories of landmarks that we identified in this study particularly to test their effectiveness in orienting someone in an unfamiliar environment.

Acknowledgments This research was supported by the German Research Foundation (DFG) with project number SCHW1371/15-1 and the ERC StRG Grant Agreement No 637645. The first author would like to thank the German Academic Exchange Service (DAAD) for granting a full doctoral scholarship. We also thank the constructive comments of the anonymous reviewers.

Open Access This article is distributed under the terms of the Creative Commons Attribution 4.0 International License (http:// creativecommons.org/licenses/by/4.0/), which permits unrestricted use, distribution, and reproduction in any medium, provided you give appropriate credit to the original author(s) and the source, provide a link to the Creative Commons license, and indicate if changes were made.

\section{References}

Allen, G. (1997). From knowledge to words to wayfinding: Issues in the production and comprehension of route directions. In S. Hirtle, \& A. Frank (Eds.), Spatial information theory a theoretical basis for GIS (Vol. 1329, pp. 363-372). Berlin: Springer. Retrieved from http://dx. doi.org/10.1007/3-540-63623-4_61

Brown, B., \& Laurier, E. (2012). The normal, natural troubles of driving with GPS. In Proceedings of the SIGCHI conference on human factors in computing systems (pp. 1621-1630). New York: ACM.

Dale, R., Geldof, S., \& Prost, J.-P. (2002). Generating more natural route descriptions. In Proceedings of the 2002 Australasian (pp. 41-48).

Daniel, M., \& Denis, M. (1998). Spatial descriptions as navigation aids: A cognitive analysis of route directions. Kognitionswissenschaft, 7(1), 45-52.

Denis, M. (1997). The description of routes: A cognitive approach to the production of spatial discourse. Cahiers de psychologie cognitive, 16(4), 409-458.

Denis, M., Pazzaglia, F., Cornoldi, C., \& Bertolo, L. (1999). Spatial discourse and navigation: An analysis of route directions in the city of Venice. Applied Cognitive Psychology, 13(2), 145-174.

Denis, M., \& Zimmer, H. (1992). Analog properties of cognitive maps constructed from verbal descriptions. Psychological Research, 54(4), 286-298.

Golledge, R. G., \& Stimson, R. (1997). Spatial behavior: A geographic perspective. New York: The Guilford Press.

Hallgren, K. A. (2012). Computing inter-rater reliability for observational data: An overview and tutorial. Tutorials in Quantitative Methods for Psychology, 8(1), 23-34.

Ishikawa, T., Fujiwara, H., Imai, O., \& Okabe, A. (2008). Wayfinding with a GPS-based mobile navigation system: A comparison with maps and direct experience. Journal of Environmental Psychology, 28(1), 74-82.
Ishikawa, T., \& Nakamura, U. (2012). Landmark selection in the environment: Relationships with object characteristics and sense of direction. Spatial Cognition \& Computation: An Interdisciplinary Journal, 12(1), 1-22.

Klippel, A. (2003). Wayfinding Choremes. In W. Kuhn, M. F. Worboys, \& S. Timpf (Eds.), Spatial information theory. Foundations of geographic information science (pp. 301-315). Berlin: Springer.

Klippel, A., \& Winter, S. (2005). Structural salience of landmarks for route directions. In COSIT'05 Proceedings of the 2005 international conference on spatial information theory (pp. 347-362). Berlin: Springer.

Krippendorff, K. (2003). Content analysis: An introduction to its methodology (2nd ed.). Thousand Oaks: Sage Publications.

Li, R., Fuest, S., \& Schwering, A. (2014). The effects of different verbal route instructions on spatial orientation. In J. Huerta, S. Schade \& C. Granell (Eds.), Short Paper Proceedings of the 17th AGILE Conference on Geographic Information Science, Castellón, Spain.

Lovelace, K. L., Hegarty, M., \& Montello, D. R. (1999). Elements of good route directions in familiar and unfamiliar environments. In COSIT ' 99 proceedings of the international conference on spatial information theory: Cognitive and computational foundations of geographic information science (pp. 65-82).

Mackaness, W., Bartie, P., \& Espeso, C. S.-R. (2014). Understanding information requirements in "Text Only" pedestrian wayfinding systems. In E. P. Matt Duckham (Ed.), Geographic information science: Proceeding in 8th international conference, GIScience 2014, Vienna, Austria. Lecture notes in computer science (Vol. 8728, pp. 235-252). Springer International Publishing.

Michon, P.-E., \& Denis, M. (2001). When and why visual landmarks used in giving directions? Spatial Information Theory. COSIT 2001, Lecture Notes in Computer Science, 2205, 292-305.

Montello, D. R., \& Sas, C. (2006). Human factors of wayfinding in navigation. In W. Karwowski (Ed.), International encyclopedia of ergonomics and human factors. London: CRC Press/Taylor \& Francis, Ltd.

Muenzer, S., Zimmer, H. D., \& Baus, J. (2012). Navigation assistance: A trade-off between wayfinding support and configural learning support. Journal of Experimental Psychology: Applied, 18(1), 18-37.

Raubal, M., \& Winter, S. (2002). Enriching wayfinding instructions with local landmarks. In M. J. Egenhofer, \& D. M. Mark (Eds.), GIScience '02 proceedings of the second international conference on geographic information science (pp. 243-259). London: Springer.

Richter, K.-F., \& Klippel, A. (2005). A model for contextspecific route directions. In M. K.-B. Christian Freksa (Ed.), Proceedings of the 4th international conference on spatial cognition: Reasoning, action, interaction (pp. 58-78). Heidelberg: Springer.

Richter, K.-F., \& Winter, S. (2014). Landmarks: GIScience for intelligent services. Heidelberg: Springer.

Schroder, C. J., Mackaness, W. A., \& Gittings, B. M. (2011). Giving the 'Right' route directions: The requirements for pedestrian navigation systems. Transactions in GIS, 15(3), 419-438. 
Schwering, A., Li, R., \& Anacta, V. J. (2013). Orientation Information in different Forms of Route Instructions. In D. Vandenbroucke, B. Bucher \& J. Crompvoets (Eds.), Short Paper Proceedings of the 15th AGILE International Conference on Geographic Information Science, Leuven, Belgium.

Schwering, A., Li, R., \& Anacta, V. J. (2014). The use of local and global landmarks across scales and modes of transportation in verbal route instructions. In Poster session presented at the 2014 Spatial Cognition Conference, Bremen, Germany.

Shrout, P. E., \& Fleiss, J. L. (1979). Intraclass correlations: Uses in assessing rater reliability. Psychological Bulletin, 86(2), 420-428.

Steck, S. D., \& Mallot, H. A. (2000). The role of global and local landmarks in virtual environment navigation. Presence: Teleoperators and Virtual Environments, 9(1), 69-83.

Taylor, H. A., \& Tversky, B. (1992). Spatial mental models derived from survey and route descriptions. Journal of Memory and Language, 31(2), 261-292. Retrieved from http://dx.doi.org/10.1016/0749-596X(92)90014-O

Tenbrink, T. (2014). Cognitive discourse analysis: Accessing cognitive representations and processes through language data. Language and Cognition: An Interdisciplinary Journal of Language and Cognitive Science, 7(1), 1-40.

Timpf, S. (2002). Ontologies of wayfinding: A traveler's perspective. Networks and Spatial Economics, 2(1), 9-33.

Timpf, S., Volta, G., Pollock, D., \& Egenhofer, M. (2005). A conceptual model of wayfinding using multiple levels of abstraction. In A. U. Frank, I. Campari, \& U. Formentini (Eds.), Theories and methods of spatio-temporal reasoning in geographic space (Vol. 639, pp. 348-367). Berlin: Springer.

Tom, A., \& Denis, M. (2003). Referring to landmark or street information in route directions: What difference does it make? In W. Kuhn, M. F. Worboys, \& S. Timpf (Eds.), Spatial information theory. Foundations of geographic information science lecture notes in computer science (Vol. 2825, pp. 362-374). Berlin: Springer.

Tomko, M., Winter, S., \& Claramunt, C. (2008). Experiential hierarchies of streets. Computers, Environment and Urban Systems, 32(1), 41-52.

Tversky, B., Lee, P., \& Mainwaring, S. (1999). Why do speakers mix perspectives? Spatial Cognition and Computation, 1(4), 399-412.

Weiser, P., \& Frank, A. U. (2013). Cognitive transactions-A communication model. In J. S. Thora Tenbrink (Ed.), Spatial information theory. Lecture notes in computer science (pp. 129-148).

Weissensteiner, E., \& Winter, S. (2004). Landmarks in the communication of route directions. Third International Conference, GIScience 2004, Lecture Notes in Computer Science, 3234, 313-326.

Winter, S., Tomko, M., Elias, B., \& Sester, M. (2008). Landmark hierarchies in context. Environment and Planning $B$ : Planning and Design, 35(3), 381-398. 